\title{
Interactive comment on "Data assimilation with multiple types of observation boreholes via ensemble Kalman filter embedded within stochastic moment equations" by Chuan-An Xia et al.
}

Chuan-An Xia et al.

c.a.xia@cugb.edu.cn

Received and published: 24 February 2021

Re: Revision of the manuscript " Data assimilation with multiple types of observation boreholes via ensemble Kalman filter embedded within stochastic moment equations" (Paper hess-2020-588) by Chuan-An Xia, Xiaodong Luo, Bill X. Hu, Monica Riva, Alberto Guadagnini.

Dear Referee\#2: 
Supplement file an itemized list of your comments together with our response to each. Comments are listed in black font and our responses in blue font. Modifications implemented in the Revised Manuscript are indicated in red in the "Article Tracked Changes" document right after our responses.

Sincerely, Chuan-An Xia, Xiaodong Luo, Bill X. Hu, Monica Riva, Alberto Guadagnini

Interactive

comment

Please also note the supplement to this comment:

https://hess.copernicus.org/preprints/hess-2020-588/hess-2020-588-AC2-

supplement.pdf

Interactive comment on Hydrol. Earth Syst. Sci. Discuss., https://doi.org/10.5194/hess-2020-

$588,2020$. 